ECONOMICS

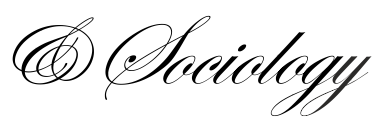

Abbasov, J., \& Karimov, K. (2020). Households survey and inflation expectation. Economics and Sociology, 13(2), 210-227. doi:10.14254/2071-789X.2020/13-2/14

\section{HOUSEHOLDS SURVEY AND INFLATION EXPECTATION}

\author{
Jeyhun Abbasov \\ Central Bank of Azerbaijan, \\ Research Department, \\ Baku, Azerbaijan \\ Azerbaijan State University of \\ Economics, Economy and \\ Administration Department, \\ Baku, Azerbaijan \\ Institute of Control Systems of \\ ANAS, \\ Baku, Azerbaijan \\ E-mail: \\ ceybunabbasoglu@gmail.com \\ ORCID 0000-0001-8187-441X
}

\author{
Khagani Karimov \\ Central Bank of Azerbaijan, \\ Monetary Policy department, \\ Baku, Azerbaijan. \\ E-mail: \\ khaganikarimov@gmail.com
}

Received: September, 2019

1st Revision: January, 2020

Accepted: June, 2020

DOI: $10.14254 / 2071-$

789X.2020/13-2/14

JEL Classification: C01, C15, C83, D12
ABSTRACT. Central Bank of Azerbaijan intends to move to the Inflation Targeting regime in the medium term. The new regime requires the development of new models and methodologies. Though the Bank's researchers have already developed different advanced models, most of them use the quantitative factor analysis of inflation. The current paper investigates an alternative approach that allows the estimation of inflation expectations by using the survey data. This approach, which has never been used before in Azerbaijan, helps to understand the behavior of the households in detail and enables converting qualitative data into quantitative data. Assuming that households' responses have normal and uniform probability distributions, the inflation expectations were estimated for the period of 2013Q32020Q1 in Azerbaijan.
Keywords: inflation expectation, household surveys, indifference intervals, forecasting error, unbiasedness of expectations, efficiency of expectations

\title{
Introduction
}

It is accepted that inflation expectations are factors in an economy that have a significant impact on headline inflation. The expectations also provide an unbiased predictor of future inflation and can measure a forward-looking analysis of price change. Thus studying and monitoring their behavior is always a vital part of policy implementation by central banks.

Some economists thought that Phillips ideas can always be appearing, and there is a permanent relationship between inflation and unemployment. However, this idea is rarely 
accepted by empirical results. The main point is that monetary policymakers sometimes let high inflation to reach the low unemployment rate, which means there is a choice between inflation and unemployment, not a relationship.

In 1970, very high inflation rate was followed by very high unemployment rate at the same time (stagflation) in many developed countries. After this event, researchers, especially Friedman (1968), criticized the theories which are based on Phillips curve. Friedman (1968) showed that Phillips curve only works for the short term. He noted that employers and employees usually contract with considering the inflation expectations in the long term. In this case, unemployment will rise again, but now with higher inflation. This shows that there is no relationship between inflation and unemployment in the long term. So, the central banks should not target the level of unemployment below the natural level. This once again shows the importance of inflation expectations. Moreover, it is well known that Central Banks usually use inflation targeting regime. In this context, the prediction of inflation expectations is very important.

According to the law, the primary target of the Central Bank of Azerbaijan (CBA) is price stability. For the decades, CBA chose a fixed exchange rate regime as the best option. The national currency was pegged to the US dollar, which had helped to maintain price stability in the economy. However, in 2015 the drop in oil prices contracted the oil revenues into the economy, consequently reduced dollar supply in the FX market. The devaluation of the main trade partners' currencies increased the physiological tension in the market. In order to keep the exchange rate of manat stable, the CBA spent a large part of its reserves. However, this step was not enough, and to attain stability in FX market and stop the depletion of the reserves, the CBA had to devalue the manat. Also, to maintain further stability in the FX market and curb the inflation, Central Bank had to look for a new nominal anchor, monetary base ${ }^{1}$. Targeting the monetary base helped to stabilize the FX market and allowed CBA to achieve macroeconomic stability for a couple of years.

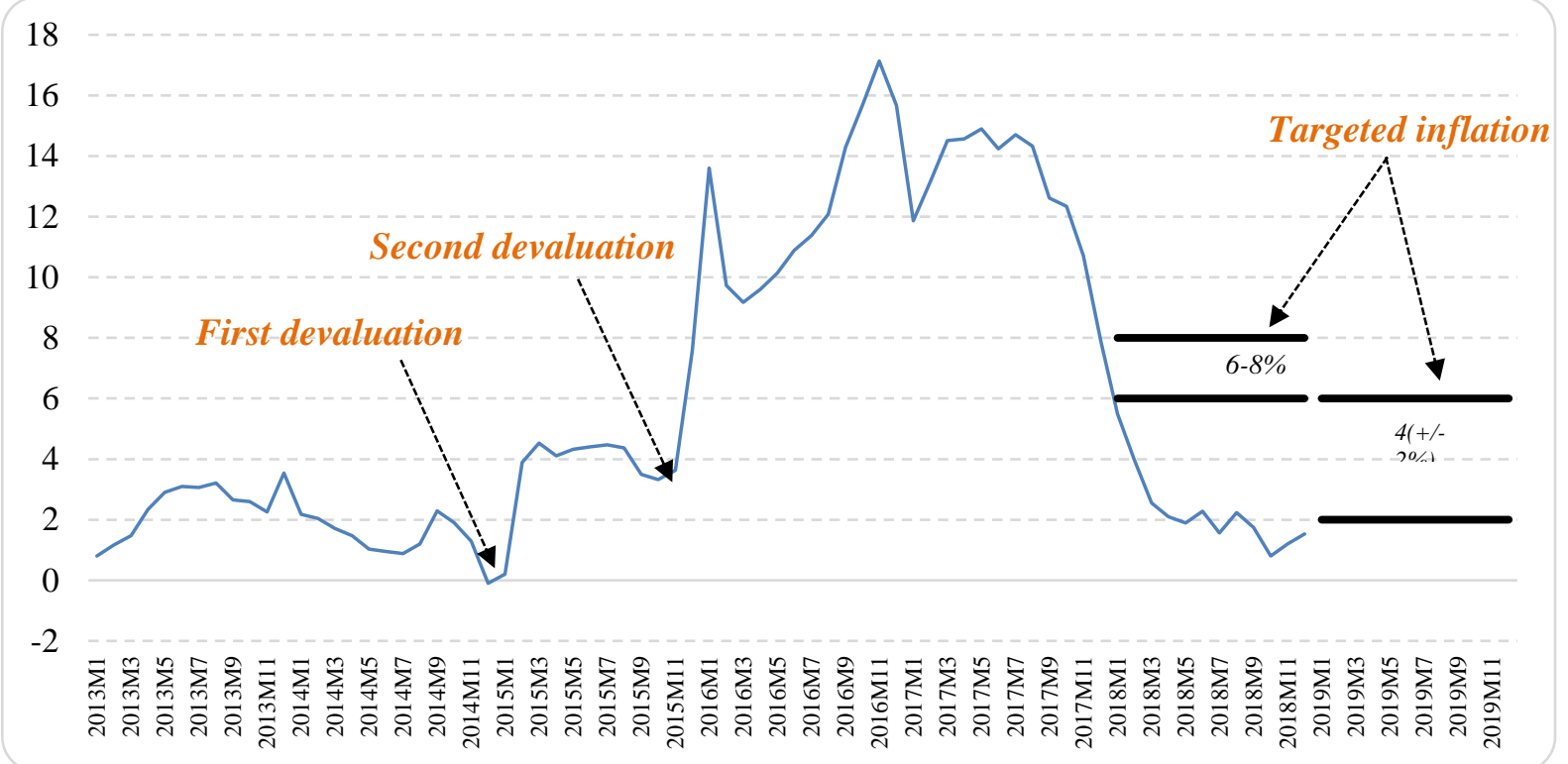

Figure 1. Inflation in Azerbaijan (percent, y.o.y.)

In medium-term, CBA intends to leave monetary targeting and move into a new regime, Inflation Targeting. IT regime will allow the central bank to increase the transmission of monetary policy and gradually move to a more flexible exchange rate. The current project is

\footnotetext{
${ }^{1}$ Monetary Base is a summation of cash in the circulation and manat reserves of banks kept at Central Bank.
} 
one of the new approaches which would allow the CBA to use the survey data and estimate inflation expectations. As the central banks take into account expected inflation to form its target, this paper's contribution may be vital. The estimation of the inflation expectations by using survey data will help understand the behavior of the respondents, and allow converting a qualitative analysis into a quantitative which has never been conducted at the CBA. Therefore, the main question of this research is to estimate the inflation expectations based on the households' survey and measure the forecasting performance of these expectations in Azerbaijan.

The research method consists of normality and uniform assumptions for the probability distribution of the expectations, calculation of the indifference intervals and cumulative probabilities. As the primary part of the research method, we also can note the calculation of the mean absolute error (MAE), and the root mean square error (RMSE) for the measures of accuracy of forecasts and the mean error (ME) for the measure of unbiasedness of expectations. Regression analysis for unbiasedness is also one of the major cornerstones of the research method. We found that the forecasting error, defined as the difference between inflation expectation and current inflation under normality assumption, is less than the forecasting error under the uniform assumption for all underlining periods. Finally, the inflation expectation was calculated for all subgroups, and the results were compared.

The results of this study may be beneficial for policy implementation regarding the nature of the inflation targeting. Consequently, research may fill the gap in the area of the prediction of inflation expectations. It should be noted that the calculation of inflation expectations on the base of the results of household surveys in Azerbaijan can be noted as the novelty of this study. The structure of the paper is as the following. Section 1 is about the literature review on the vital research works in this field. Database and survey design, which consists of an explanation of the questions about price change expectation and kind of the answers to this question, is discussed in Section 2. The methodology has been discussed in Section 3. Here we tried to give the information about the assumptions on the probability distribution of inflation expectations. In Section 4, empirical results on the calculating on inflation expectations and forecasting performance or properties of inflation expectations were summarized. At the end, there are conclusion and references sections.

\section{Literature review}

Theil (1952) prepared the probability estimation of the production index on base of monthly survey of firms. There were three type answers of the question about the change of production index in this survey. Firms reported that their production index will decrease or will increase or will not change. Theil (1952) had considered the fraction of unit firms reporting a decrease, an increase and "no change" and denote them by $d_{t}, s_{t}$ and $c_{t}$ respectively on base of Anderson's procedure. He argued that, the production index of some firms will increase as small number $p$. But in fact these firms have replied "no change" to the survey. Let us express this statement with his words: "There exists an interval $(-p, p), p$ being positive, such that, for any $i$ and $t$, the unit firm $i$ reports "no change" in month $t$ if and only if $y_{i t}$ lies in this interval. The interval $(-p, p)$ will be called the indifference interval" (Theil, 1952, pp. 107). Where, $y_{t}$ is the first difference of the (total) production index. He supposed that the frequency distribution of production index is normal distribution with both constant variance and changing variance or rectangular distribution with constant range.

In another research which has been introduced by Carlson and Parkin (1975) had been estimated the inflation expectations. They showed that how an estimate of the expected inflation rate may be obtained from the qualitative data generated by surveys. Their data base consists of the results of monthly survey which was organized among approximately 1000 individuals 
in Great Britain. In this survey, respondents can choose one of three type answers to questionnaires: prices will go up, go down or stay the same over the next six months. Respondents can also provide answer "don't know". So, it means that there are four response categories in Carlson and Parkin (1975) approach and proportions of the total response for these categories have been computed as follows: 1) proportion of "go up" $\left(A_{t}\right)=$ number of response "go up" / total response; 2) proportion of "go down" $\left(B_{t}\right)=$ number of response "go down" / total response; 3$)$ proportion of "stay the same" $\left(C_{t}\right)=$ number of response "stay the same" / total response; 4) proportion of "don't know" $\left(D_{t}\right)=$ number of response "don't know" / total response.

Arnold and Lemmen (2008) used the European Commission's Consumer Survey to estimate whether inflation expectations have converged and whether inflation uncertainty has diminished in Europe. They found that inflation expectations depend more on past national inflation rates than on the ECB's mainstay for price stability based on the household survey. Inflationary expectations do not faster converge than the actual rate of inflation. Regarding the uncertainty of inflation, the data show a correlation with the size of the country after the introduction of the euro. This suggests that inflation uncertainty may increase in countries with less influence on ECB policies in the framework of EMU.

Ehrmann et al. (2015) analyzed consumer expectations for inflation using micro-level data from a University of Michigan consumer survey. Their research shows that in addition to socio-economic factors such as income, age, and gender; other characteristics of households, such as financial status and attitudes toward purchases, are also important factors in determining the accuracy of an inflation forecast. They show that respondents who are pessimistic about current or future financial conditions and basic consumption; as well as those who expect future incomes to decline, tend to have higher expectations than other households.

Arioli et al. (2017) update and broaden the preliminary assessment of consumer perceptions and expectations regarding quantitative inflation in the Euro zone and the EU, using anonymous micro data collected by the European Commission in the context of the Harmonised EU Programme of Business and Consumer Surveys. They argued that results of quantitative estimation of consumer inflation were higher than HICP (Adjusted Consumer Price Index) inflation during the sampling period (2004-2015).

Using a unique "information experience" included in the online survey, Armona et al. (2019) examined how consumer price expectations for housing respond to increases in home prices and how they affect investment decisions. After studying the respondents' a priori views on past and future changes in local housing prices, they compiled a unique information panel, taking a random portion of them. They believe that this allows identification of these effects and is a step towards the process of creating expectations. This study argues that a review of long-term expectations shows that respondents do not expect an empirically significant return on rising home prices.

Szyszko et al. (2020) studied whether consumer inflation expectations in the EU and found that Member States were more forward-looking after the onset of the financial crisis (October 2008-2016) and after the most turbulent times (2013-2016). They evaluated the hybrid specification of expectations by studying the characteristics of expectations, in other words, the errors and the macroeconomic efficiency of expectations. Researchers have shown that the characteristics of expectations have changed in the context of low inflation and deflation after the crisis, and concluded that the article contributed to the literature on the characteristics of expectations in E.U.

Focusing on the post-1995 deflation period, Diamond et al. (2020) examined the link between inflation and household expectations in Japan. Their primary outcome is an increase in inflation expectations with age. Another result is that measured inflation also increases with age, although it continues to show a positive correlation between age and inflation expectations. 
Their results show that the price level in the general basket remains stable until the age of 4044 , and then begins to grow to the age of 65 . Household inflation also varies by age group and generally increases with age, peaking at 55-59 years of age.

In addition, Johannsen (2014), Kaplan and Schulhofer-Wohl (2017), Ueno and Namba (2013), Drager (2015), Kokoszczynski et al. (2010), Łyziak (2009, 2010, 2013), Łyziak and Mackiewicz (2014), Miah et al. (2016) etc. are interesting research works in this field.

Finally, we summarized the categories of responses, assumptions for the distribution of the expectations and research area of some works which have been devoted estimation of inflation expectations by using consumer survey data in Table 1. This information will be useful for construction of our research strategy.

Table 1. Some research papers

\begin{tabular}{|c|c|c|c|}
\hline Author(s) & Categories of responses & $\begin{array}{l}\text { Distribution of } \\
\text { the } \\
\text { expectations }\end{array}$ & Area \\
\hline $\begin{array}{l}\text { Carlson and } \\
\text { Parkin (1975) }\end{array}$ & $\begin{array}{l}\text { 1. prices up } \\
\text { 2. prices down } \\
\text { 3. no change } \\
\text { 4. don't know }\end{array}$ & Normal & United Kingdom \\
\hline $\begin{array}{l}\text { Batchelor and } \\
\text { Orr (1988) }\end{array}$ & $\begin{array}{l}\text { 1. prices will fall } \\
\text { 2. prices stay the same } \\
\text { 3. prices rise }\end{array}$ & Logistic & United Kingdom \\
\hline Lyziak (2003) & $\begin{array}{l}\text { 1. rise faster than at present, } \\
\text { 2. rise at the same rate, } \\
\text { 3. rise more slowly, } \\
\text { 4. stay at their present level, } \\
\text { 5. go down } \\
\text { 6. difficult to say }\end{array}$ & $\begin{array}{l}\text { Normal, } \\
\text { Uniform }\end{array}$ & Poland \\
\hline Dias etc. (2010) & $\begin{array}{l}\text { 1. increase more rapidly } \\
\text { 2. increase at the same rate } \\
\text { 3. increase at a slower rate } \\
\text { 4. stay about the same } \\
\text { 5. fall } \\
\text { 6. don't know }\end{array}$ & Normal & Euro area \\
\hline $\begin{array}{l}\text { Forsells and } \\
\text { Kenny (2002) }\end{array}$ & $\begin{array}{l}\text { 1. there will be a more rapid increase in } \\
\text { prices } \\
\text { 2. prices will increase at the same rate } \\
\text { 3. prices will increase at a slower rate } \\
\text { 4. prices will stay about the same or } \\
\text { 5. prices will fall slightly }\end{array}$ & Normal & Euro area \\
\hline
\end{tabular}

\section{Data and survey design}

Our data base consists of the results of households' quarterly survey which is realized by Central Bank of Azerbaijan for period of 2013Q3-2020Q1. In total, 4252 households are included in this survey and these individuals are divided into 6 groups; income, type of activity, work regime (part or full time), education, age, and gender. 15 questions include in this survey and the detailed results of the survey are confidential and cannot be reported in this paper. One of these questions is about price change expectation. This is following:

Q6: How will consumer prices change over the next 12 months?

(1) rise faster than present, 
(2) rise at the same rate,

(3) rise more slowly,

(4) stay at the present level,

(5) go down,

Let $a, b, c, d$ and $e$ are fractions and defined as following:

Where,

$$
\begin{gathered}
a=\frac{n_{\text {go down }}}{N_{\text {total response }}} \\
b=\frac{n_{\text {stay at their present level }}}{N_{\text {total response }}} \\
c=\frac{n_{\text {rise more slowly }}}{N_{\text {total response }}} \\
d=\frac{n_{\text {rise at the same rate }}}{N_{\text {total response }}} \\
e=\frac{n_{\text {rise faster than at present }}}{N_{\text {total response }}}
\end{gathered}
$$

$\mathrm{n}$ - the number of responses of each specific answer,

$\mathrm{N}$ - the number of total responses

So, we can introduce these fractions of respondents, excluding "don't knows"; those who think prices will go down or stay at their present level, or rise more slowly or rise at the same rate or rise faster than at present. It means that choosing any one of these responses by respondents has the same probability. Therefore, we can construct the balance as following: $a+$ $b+c+d+e=1$

\section{Methodological approach}

After investigation of some research works, we defined three major cornerstones of the estimation of inflation expectation based on consumer survey. These are probability distribution of the expectations, the indifference intervals and cumulative probabilities.

\subsection{Probability distribution of the expectations}

Probability distribution of the expectations is the first cornerstone of this methodology.

Normal distribution of the expectations:

Suppose that $\pi_{i}^{e}$ is the percentage change in the $i^{\text {th }}$ respondent's price index over the next twelve months and $f_{t}\left(\pi_{i}^{e}\right)$ is the subjective probability density function of $\pi_{i}^{e}$ for a respondent $i$ during quarter $t$. Carlson and Parkin (1975) used the normal distribution for this statement. Contrary, Batchelor and Orr (1988) note that the expectations distribution has centrally concentrate, but cannot say that it is strictly normal. They argued that individual subjective probability density functions are unlikely to be the result of independent random sampling. They accepted that $f$ is logistic by following Fishe and Lahiri (1981).

So, if we assume that individual subjective probability density function comes from the result of independent random sampling (Batchelor and Orr, 1988) and since the number of individuals asked is large (Knöbl,1974), then we can accept normality assumption for our case. The shape of this distribution has been given in Figure 2. 


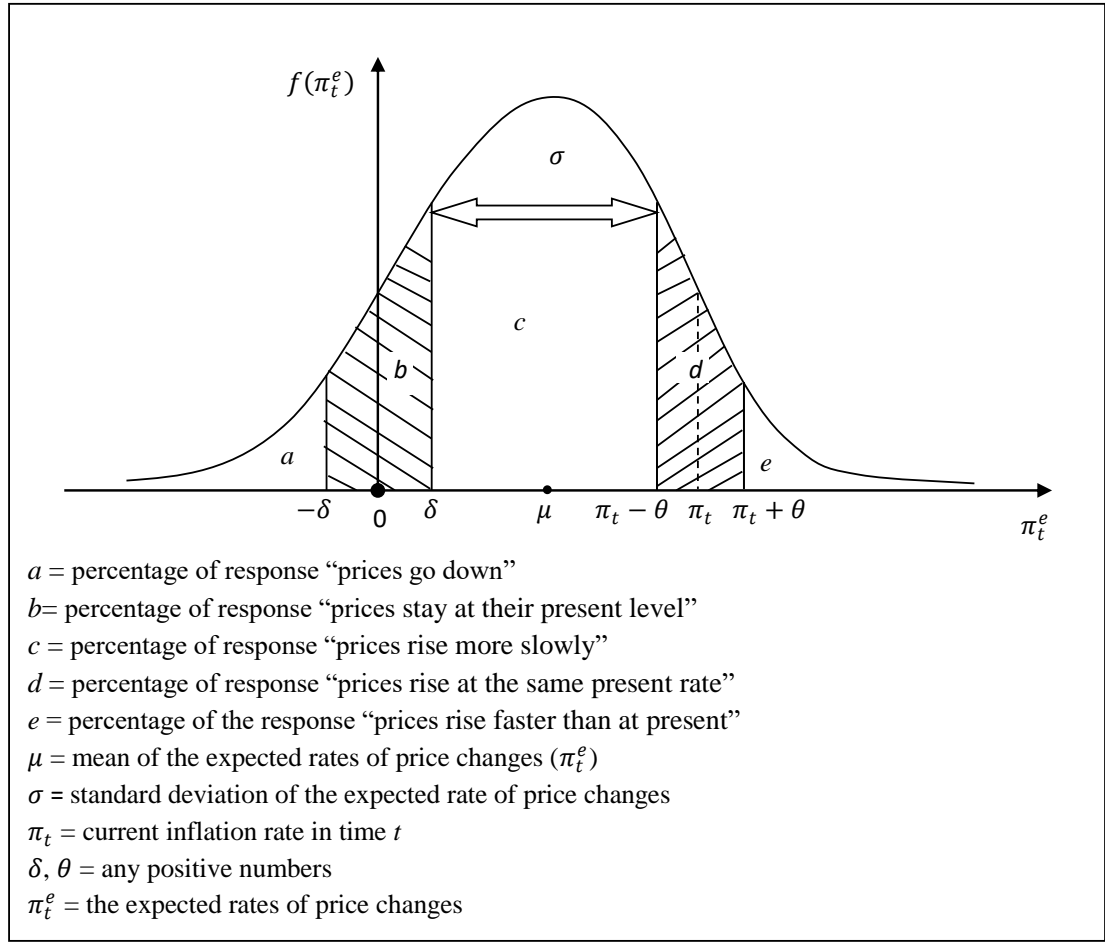

Figure 2. Normal distribution of the expected rate of price change

\section{Uniform distribution of the expectations:}

Uniform distribution is our second assumption about the probability distribution of the expectations. We think that this distribution also can be successful to estimate inflation expectation on the base of households' survey. Lyziak (2003) had used this distribution function to estimate inflation expectations in Poland. When uniform distribution is used to estimate inflation expectation there is one advantage and one disadvantage of this distribution.

In fact, it seems more reasonable that, smaller part of respondents will answer "prices go down" and "prices rise faster than at present". Contrary, we can believe that bigger part of respondents will answer "prices rise at the same present rate" and "prices rise more slowly". Such as distribution likes look the normal distribution. It is advantage of normality assumption of the distribution of responses. But under uniform assumption, it is supposed that probability of the falling of randomly selected response into any fraction (see Figure 3 ) is equal. It is disadvantage of uniform assumption of the distribution of responses. On the other hand, under normality assumption we suppose that the expected rate of price change can take very big $(+\infty)$ and very small value $(-\infty)$. This can be introduced as the disadvantage of normality assumption. Contrary, under uniform assumption we suppose that the expected rate of price change is defined between two points $(\mu-\tau$ and $\mu+\tau)$. This can be introduced as the advantage of uniform assumption. 


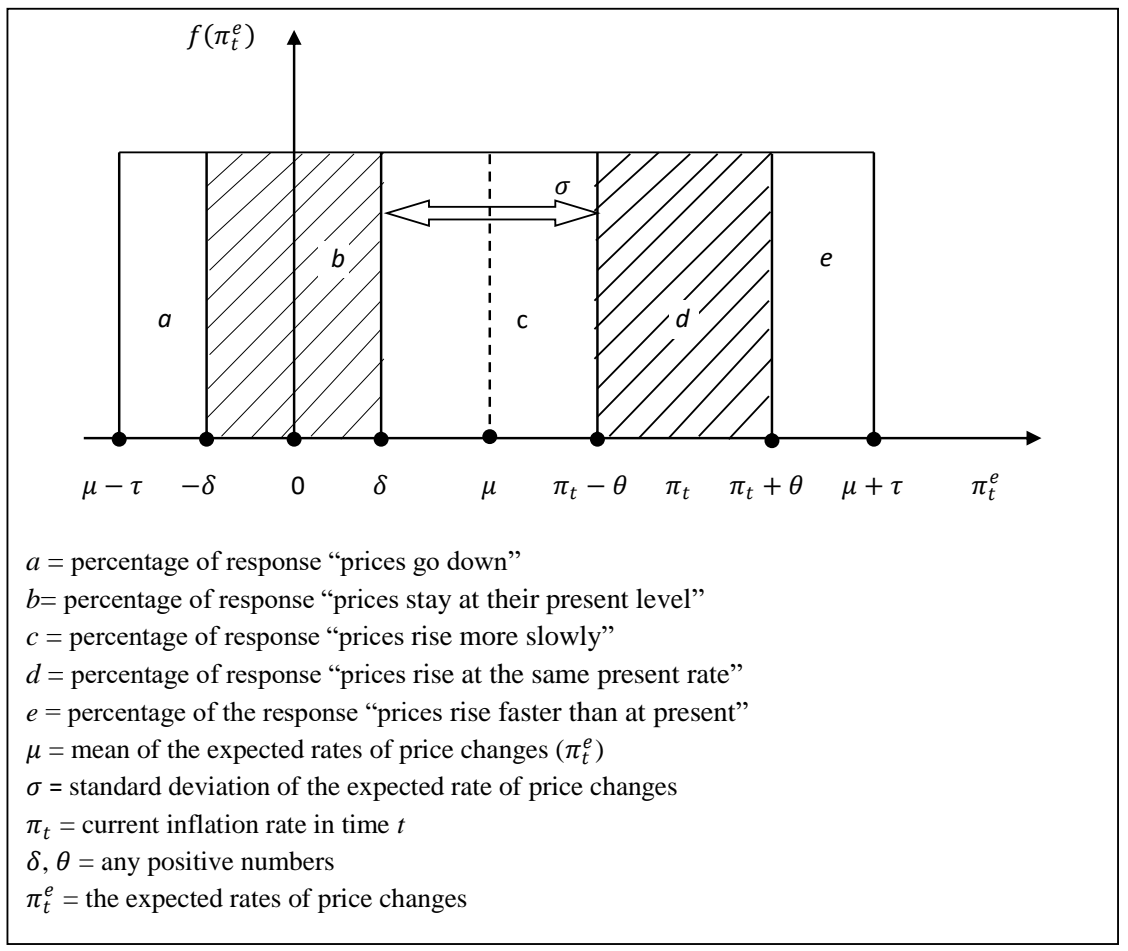

Figure 3. Uniform distribution of the expected rate of price change

\subsection{The indifference intervals}

In this part we will define indifference intervals which play very important to compute the inflation expectations on the base of households' survey. So, we have 5 indifference intervals (see Figure 2) and we can describe them as the following:

1) $(-\delta ; \delta)$. It is clear that, this interval is the symmetric around 0 . So, if more than one half of the probability density distribution $f_{t}\left(\pi_{i}^{e}\right)$ for respondent $i$ lies into this interval, then this respondent chooses the answer "prices stay at their present level". Here we need to interpret parameter $\delta$. Suppose that respondent 1 chooses answer (4) to question Q6 (see Section 1) for the next 12 months. It means that the percentage change of this respondent's commodity price index must be equal to 0 during the next 12 months. But it is clear that the percentage change of this price index will not be always equal to exactly 0 . These changes will distribute with any standard deviation $\varphi_{1}$ around 0 . Analogously, we can continue the same opinion for other respondents. For example, for respondent 2 the percentage change of commodity price index will distribute with standard deviation $\varphi_{2}$ around 0 . So, with the same pattern, for respondent $n$ the percentage change of commodity price index will distribute with standard deviation $\varphi_{n}$ around 0 . Now we can accept $\delta$ as the average of $\varphi_{1}, \varphi_{2}, \ldots, \varphi_{n}$. In this case, mean percentage change of commodity price index will distribute with standard deviation $\delta$ around 0 across all individuals.

2) $\left(\pi_{t}-\theta ; \pi_{t}+\theta\right)$. We can see that this interval is the symmetric around $\pi_{t}$. Where, $\pi_{t}$ is the current inflation rate and $\theta$ is any positive number. If more than one half of the probability density distribution $f_{t}\left(\pi_{i}^{e}\right)$ for respondent $i$ lies into this interval, then this respondent chooses the answer "prices rise at the same rate as present". Let's interpret the parameter $\theta$ with the same pattern in first interval. Suppose that respondent 1 chooses answer (2) to question Q6 (see Section 1) for the next 12 months. It means that the percentage change of this respondent's commodity price index must be equal to $\pi_{t}$ during the next 12 months. But it is clear that the change of this price index will not be always equal to exactly $\pi_{t}$. These percentage changes will 
distribute with any standard deviation $\xi_{1}$ around $\pi_{t}$. Analogously, we can continue same opinion for other respondents. For example, for respondent 2 the percentage change of commodity price index will distribute with standard deviation $\xi_{2}$ around $\pi_{t}$. So, with the same pattern, for respondent $n$ the percentage change of commodity price index will distribute with standard deviation $\xi_{n}$ around $\pi_{t}$. Now we can accept $\theta$ as the average of $\xi_{1}, \xi_{2}, \ldots, \xi_{n}$. In this case, mean percentage change of commodity price index will distribute with standard deviation $\theta$ around $\pi_{t}$ across all individuals.

3) $\left(\pi_{0}+\theta ;+\infty\right)$. If more than one half of the probability density distribution $f_{t}\left(\pi_{i}{ }^{e}\right)$ for respondent $i$ lies into this interval, then this respondent chooses the answer "prices rise faster than at present".

4) $\left(\delta ; \pi_{t}-\theta\right)$. If more than one half of the probability density distribution $f_{t}\left(\pi_{i}{ }^{e}\right)$ for respondent $i$ lies into this interval, then this respondent chooses the answer "prices rise more slowly".

5) $(-\infty ;-\delta)$. If more than one half of the probability density distribution $f_{t}\left(\pi_{i}^{e}\right)$ for respondent $i$ lies into this interval, then this respondent chooses the answer "prices go down".

\subsection{Cumulative probabilities and solutions}

In Section 1, $a, b, c, d$ and $e$ have been introduced as the fractions. At the same time, from Figure 2 and Figure 3, they are also corresponding probabilities for the individuals' responds. For example $a$ is equal to the probability that the random variable $\pi_{t}^{e}$ (expected rate of price change) takes a value smaller than $-\delta$. Analogously, $b$ is equal to the probability that the random variable $\pi_{t}^{e}$ takes a value between $-\delta$ and $\delta ; c$ is equal to the probability that the random variable $\pi_{t}^{e}$ takes a value between $\delta$ and $\pi_{t}-\theta ; d$ is equal to the probability that the random variable $\pi_{t}^{e}$ takes a value between $\pi_{t}-\theta$ and $\pi_{t}+\theta$ and $e$ is equal to the probability that the random variable $\pi_{t}^{e}$ takes a value greater than $\pi_{t}+\theta$. These statements can be expressed by statistical formulas as the following:

Under normality assumption:

$$
\begin{gathered}
a=\operatorname{Pr}\left(\pi^{e}<-\delta\right)=F\left(\pi^{e}<-\delta\right) \\
b=\operatorname{Pr}\left(-\delta<\pi^{e}<\delta\right)=F\left(\pi^{e}<\delta\right)-F\left(\pi^{e}<-\delta\right) \\
c=\operatorname{Pr}\left(\delta<\pi^{e}<\pi_{0}-\theta\right)=F\left(\pi^{e}<\pi_{0}-\theta\right)-F\left(\pi^{e}<\delta\right) \\
d=\operatorname{Pr}\left(\pi_{0}-\theta<\pi^{e}<\pi_{0}+\theta\right)=F\left(\pi^{e}<\pi_{0}+\theta\right)-F\left(\pi^{e}<\pi_{0}-\theta\right) \\
e=\operatorname{Pr}\left(\pi^{e}>\pi_{0}+\theta\right)=1-F\left(\pi^{e}<\pi_{0}+\theta\right)
\end{gathered}
$$

(3.1)-(3.5) equation system gives us the following solutions:

$$
\begin{aligned}
\sigma & =\frac{-2 \pi_{0}}{a^{\prime}+b^{\prime}-\left(c^{\prime}+d^{\prime}\right)} \\
\delta & =\frac{-\pi_{0}\left(b^{\prime}-a^{\prime}\right)}{a^{\prime}+b^{\prime}-\left(c^{\prime}+d^{\prime}\right)} \\
\mu & =\frac{\pi_{0}\left(a^{\prime}+b^{\prime}\right)}{a^{\prime}+b^{\prime}-\left(c^{\prime}+d^{\prime}\right)} \\
\theta & =\frac{\pi_{0}\left(c^{\prime}-d^{\prime}\right)}{a^{\prime}+b^{\prime}-\left(c^{\prime}+d^{\prime}\right)}
\end{aligned}
$$

Where,

$a^{\prime}=N_{z}^{-1}(a), \quad b^{\prime}=N_{z}^{-1}(a+b), \quad c^{\prime}=N_{z}^{-1}(a+b+c), \quad d^{\prime}=N_{z}^{-1}(a+b+c+d)$. Note that $N_{z}^{-1}$ is the inverse function of standard normal density function.

Under uniform assumption:

$$
\begin{gathered}
a=\frac{1}{2 \tau}(-\delta-\mu+\tau) \\
b=\frac{1}{\tau} \delta \\
c=\frac{1}{2 \tau}\left(\pi_{0}-\theta-\delta\right)
\end{gathered}
$$




$$
\begin{gathered}
d=\frac{1}{\tau} \theta \\
e=\frac{1}{2 \tau}\left(\mu+\tau-\pi_{0}-\theta\right)
\end{gathered}
$$

(3.10) - (3.14) equation system gives us the following solutions:

$$
\begin{aligned}
\mu & =\frac{\pi_{0}(1-2 a-b)}{2 c+b+d} \\
\tau & =\frac{\pi_{0}}{2 c+b+d} \\
\delta & =\frac{\pi_{0} b}{2 c+b+d} \\
\theta & =\frac{\pi_{0} d}{2 c+b+d}
\end{aligned}
$$

\section{Empirical results}

\subsection{Current and expected inflations}

Now we can begin to estimate inflation expectations under two assumptions about

\begin{tabular}{|c|c|c|c|c|c|c|c|c|c|c|c|}
\hline \multirow{3}{*}{ Time } & \multirow{3}{*}{$\pi_{t}$} & \multicolumn{8}{|c|}{$\pi^{e}$} & \multirow{2}{*}{\multicolumn{2}{|c|}{$\begin{array}{l}\text { Forecasting error } \\
\left(\Delta_{t}\right)\end{array}$}} \\
\hline & & \multicolumn{3}{|c|}{ Normal distribution } & \multicolumn{5}{|c|}{ Uniform distribution } & & \\
\hline & & $\mu$ & $\delta$ & $\theta$ & $\sigma$ & $\mu$ & $\delta$ & $\theta$ & $\tau$ & Normal & Uniform \\
\hline $2013 Q 3$ & 2.3 & 1.27 & 0.77 & 0.80 & 0.96 & 1.26 & 0.52 & 0.70 & 1.84 & -1.03 & -1.04 \\
\hline $2013 Q 4$ & 2.4 & 1.43 & 0.81 & 0.72 & 0.96 & 1.36 & 0.46 & 0.66 & 1.85 & -0.97 & -1.04 \\
\hline 2014Q1 & 2.0 & 1.21 & 0.65 & 0.65 & 0.81 & 1.16 & 0.37 & 0.61 & 1.57 & -0.79 & -0.84 \\
\hline 2014Q2 & 1.6 & 0.89 & 0.53 & 0.54 & 0.66 & 0.88 & 0.35 & 0.47 & 1.26 & -0.71 & -0.72 \\
\hline $2014 Q 3$ & 1.5 & 0.87 & 0.50 & 0.46 & 0.65 & 0.84 & 0.32 & 0.42 & 1.20 & -0.63 & -0.66 \\
\hline $2014 Q 4$ & 1.4 & 0.80 & 0.46 & 0.48 & 0.60 & 0.78 & 0.31 & 0.43 & 1.13 & -0.60 & -0.62 \\
\hline 2015Q1 & 2.8 & 1.99 & 0.93 & 0.77 & 1.22 & 1.84 & 0.42 & 0.89 & 2.30 & -0.81 & -0.96 \\
\hline 2015Q2 & 3.5 & 2.04 & 1.13 & 1.06 & 1.51 & 1.96 & 0.71 & 0.96 & 2.77 & -1.46 & -1.54 \\
\hline $2015 Q 3$ & 3.7 & 2.39 & 1.20 & 1.18 & 1.60 & 2.28 & 0.65 & 1.22 & 3.00 & -1.31 & -1.42 \\
\hline $2015 Q 4$ & 4.0 & 2.47 & 1.26 & 1.34 & 1.80 & 2.40 & 0.76 & 1.32 & 3.29 & -1.53 & -1.60 \\
\hline $2016 Q 1$ & 10.8 & 6.52 & 3.56 & 3.42 & 4.62 & 6.25 & 2.13 & 3.26 & 8.63 & -4.28 & -4.55 \\
\hline 2016Q2 & 10.5 & 6.38 & 3.45 & 3.30 & 4.50 & 6.11 & 2.04 & 3.17 & 8.39 & -4.12 & -4.39 \\
\hline $2016 Q 3$ & 11.2 & 6.82 & 3.67 & 3.53 & 4.83 & 6.54 & 2.17 & 3.41 & 8.98 & -4.38 & -4.66 \\
\hline $2016 Q 4$ & 12.4 & 9.69 & 3.36 & 3.90 & 5.61 & 9.22 & 1.28 & 4.98 & 10.72 & -2.71 & -3.18 \\
\hline 2017Q1 & 13.2 & 10.27 & 3.42 & 4.09 & 5.94 & 9.76 & 1.28 & 5.18 & 11.29 & -2.93 & -3.44 \\
\hline 2017Q2 & 13.90 & 9.54 & 4.02 & 4.28 & 5.73 & 9.06 & 1.74 & 4.71 & 11.00 & -4.36 & -4.84 \\
\hline $2017 Q 3$ & 13.90 & 10.37 & 3.73 & 4.44 & 6.05 & 9.89 & 1.46 & 5.39 & 11.58 & -3.53 & -4.01 \\
\hline 2017Q4 & 13.40 & 8.46 & 2.92 & 3.23 & 5.52 & 8.02 & 1.35 & 3.01 & 9.75 & -4.94 & -5.38 \\
\hline 2018Q1 & 4.00 & 2.33 & 1.06 & 0.95 & 1.69 & 2.22 & 0.60 & 0.81 & 2.95 & -1.67 & -1.78 \\
\hline 2018Q2 & 3.00 & 1.73 & 0.81 & 0.85 & 1.28 & 1.69 & 0.48 & 0.74 & 2.27 & -1.27 & -1.31 \\
\hline 2018Q3 & 2.60 & 1.60 & 0.79 & 0.69 & 1.12 & 1.50 & 0.44 & 0.65 & 2.01 & -1.00 & -1.10 \\
\hline 2018Q4 & 2.30 & 1.33 & 0.47 & 0.94 & 1.01 & 1.41 & 0.29 & 0.85 & 1.85 & -0.97 & -0.89 \\
\hline 2019Q1 & 2.10 & 1.26 & 0.46 & 0.78 & 0.88 & 1.29 & 0.26 & 0.72 & 1.63 & -0.84 & -0.81 \\
\hline 2019Q2 & 2.50 & 1.31 & 0.58 & 0.87 & 1.03 & 1.37 & 0.39 & 0.67 & 1.88 & -1.19 & -1.13 \\
\hline $2019 Q 3$ & 2.60 & 1.50 & 0.60 & 0.94 & 1.03 & 1.54 & 0.33 & 0.81 & 1.96 & -1.10 & -1.06 \\
\hline $2019 Q 4$ & 2.60 & 2.18 & 0.72 & 0.98 & 1.73 & 2.19 & 0.43 & 1.03 & 2.91 & -0.42 & -0.41 \\
\hline 2020Q1 & 3.00 & 2.86 & 0.83 & 1.02 & 2.42 & 2.84 & 0.53 & 1.25 & 3.86 & -0.14 & -0.16 \\
\hline
\end{tabular}
distribution of the expectations which have been introduced in Section 2. So, we can get the expectations both under normality assumption and uniform assumption by using solutions (3.6) - (3.9) and (3.15) - (3.18). The results of computation for total sample (without groups) were summarized in Table 2.

Table 2. The results of estimation expectations

Note: $\Delta_{t}=\pi_{t}^{e}-\pi_{t}$ 
Now we will try to interpret the results in Table 2. Let's begin from the results for normal distribution in any time point (for example for 2013Q3). The current rate of inflation at that time stood at $2.3 \%$, while the mean of the expected rate of price change over the next 12 months was estimated at $1.27 \%$ in 2013Q3. We know from Section 2 that $\delta$ and $\theta$ are parameters which determine the indifference intervals. These parameters are equal to 0.77 and 0.80 , respectively for normal distribution. Which means the respondents reporting that, prices over the next 12 months would rise at the same rate believed that, in the corresponding month of the following year annual inflation would fall within the interval $(1.5 \% ; 3.1 \%)$. While those respondents reporting that, prices would stay at their present level believed that, price growth over the next 12 months would fall within the interval $(-0.77 \% ; 0.77 \%)$. With the same pattern we can interpret the results for uniform distribution in 2013Q3. So, the mean of the expected rate of price change over the next 12 months was estimated at $1.26 \%$. The parameters $\delta$ and $\theta$ are equal to 0.52 and 0.70 , respectively. Meaning that, the respondents reporting that prices over the next 12 months would rise at the same rate believed that, in the corresponding month of the following year annual inflation would fall within the interval $(1.6 \% ; 3.0 \%)$. While those respondents reporting that, prices would stay at their present level believed that price growth over the next 12 months would fall within the interval $(-0.52 \% ; 0.52 \%)$. In Figure 4, the movement of both - current inflation and expectations has been described.

We easily can see that, for all period expectations curves are above the current inflation curve. Other hands from 2013Q3 till 2015Q1, expectation curves are close to the current inflation curve (but they are not overlapping) while from 2015Q1 till 2017Q4 it departs from the current inflation curve. Despite this, note that these curves demonstrate the same pattern for all period. These two points (non-overlapping but the same pattern) encouraged us to analyze the unbiasedness of inflation expectations.

In Figure 5, the estimation of aggregate household inflation expectations illustrates that inflation will increase for all quarters of 2020. The tendency will continue even in 2021. 
Group - Income; Subgroup - $\mathbb{1}<300$
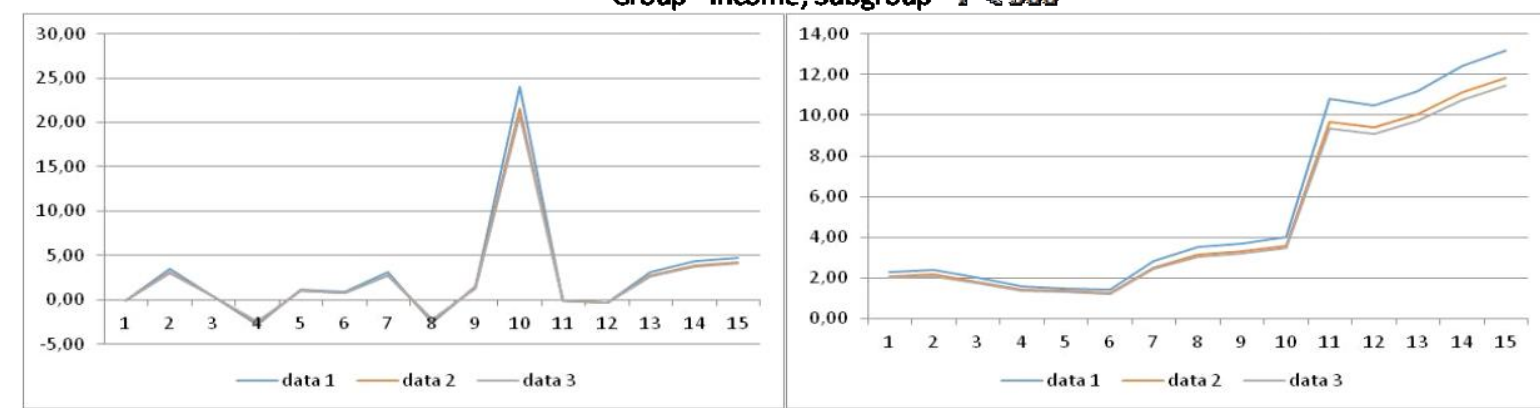

Group - Income; Subgroup - $300 \mathbb{1} \$ 70$
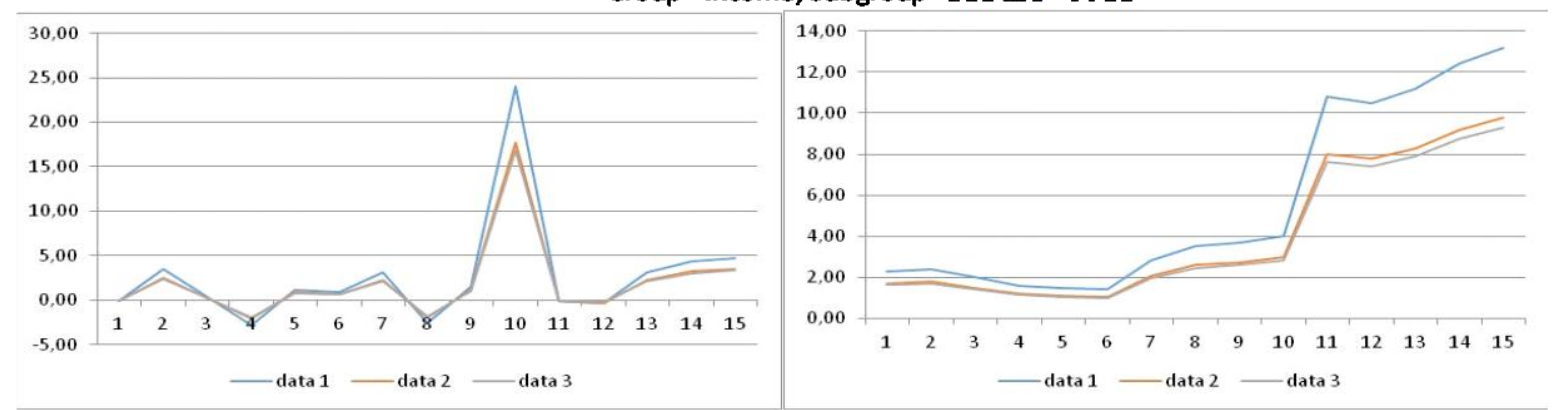

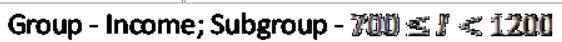

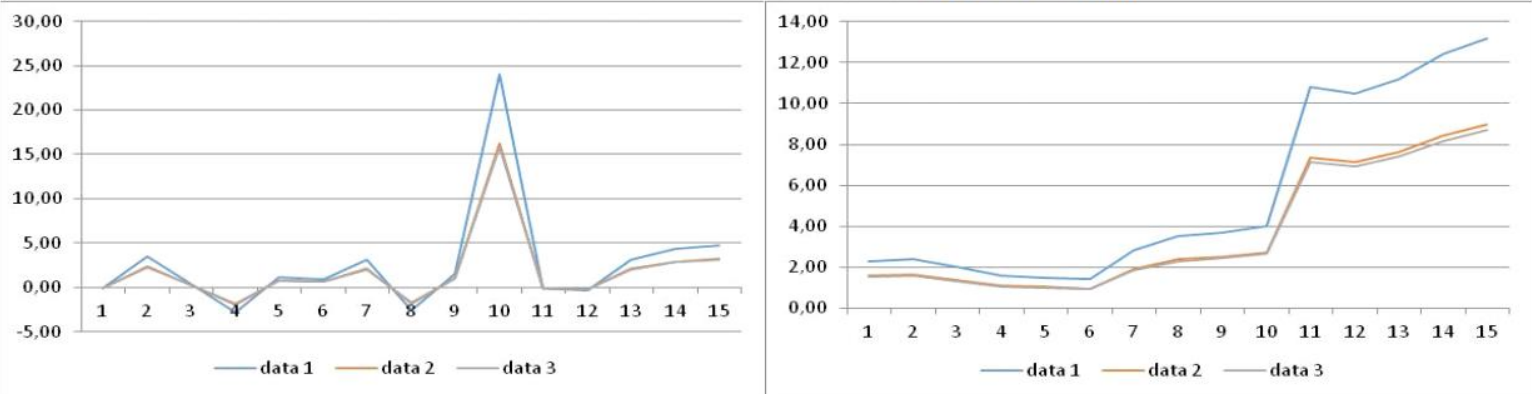

Group - Income; Subgroup - I 1200
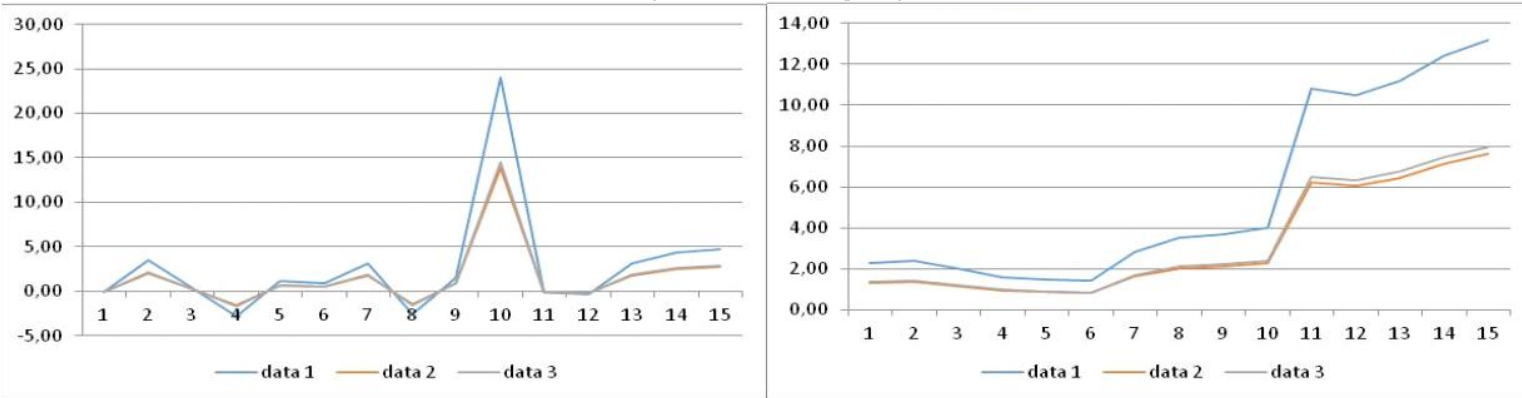

Figure 4. Current inflation and expectations for income group

Note: data 1 = current inflation; data $2=$ the mean of the expected rate of price change under normality assumption; data $3=$ the mean of the expected rate of price change under uniform assumption 


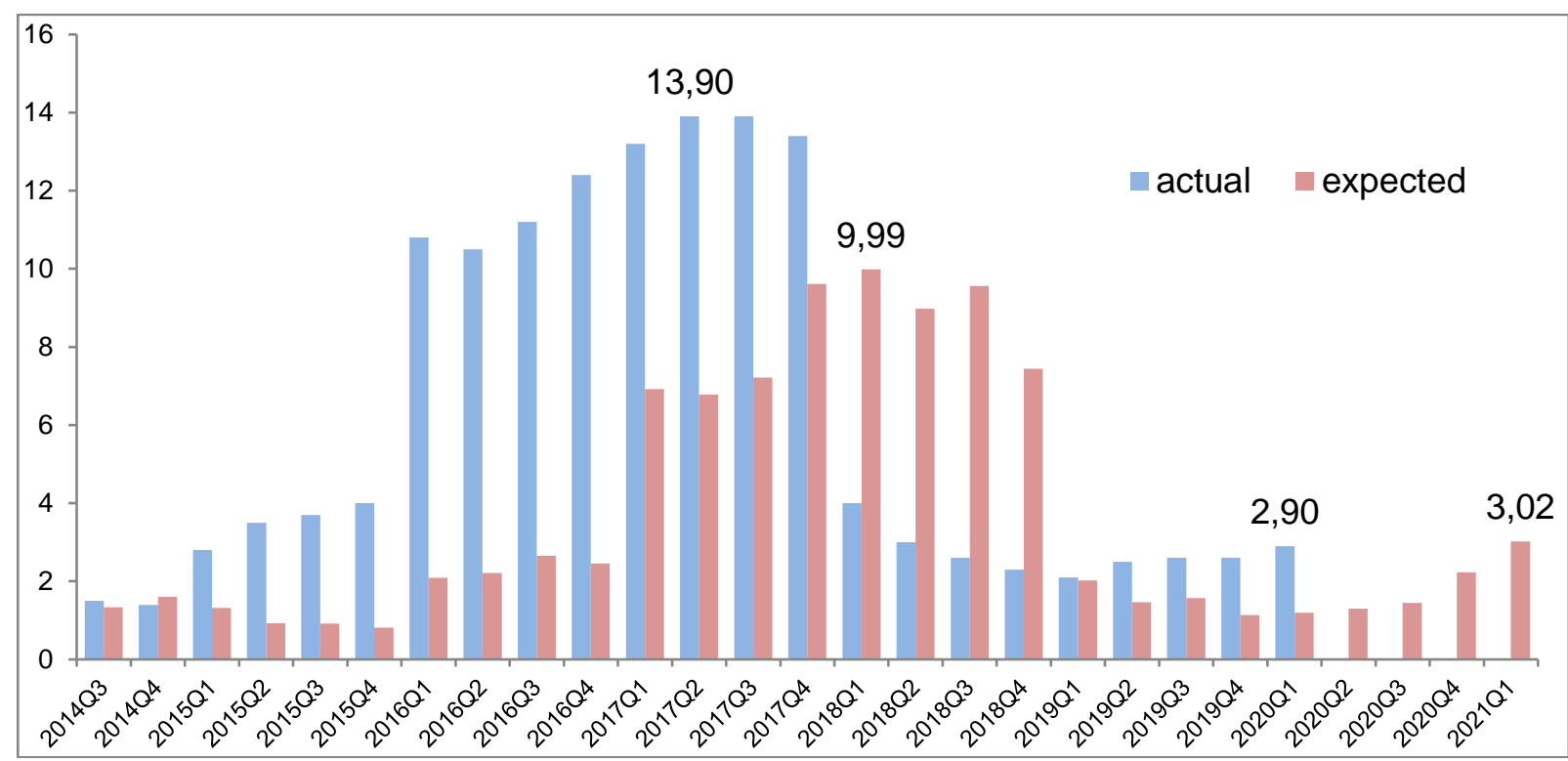

Figure 5. Current inflation and aggregate expected inflation

\subsection{Forecasting performance or properties of inflation expectations}

Muth (1961) showed that the assumption of rationality provides accuracy of calculated inflation expectations. In this context, Lloyd (1999) noted that inflation forecasting performance can be characterized by two major properties: unbiasedness and efficient of inflation expectations. He noted: "If inflation expectations are fully rational, they should exhibit two fundamental characteristics. First, they should be unbiased-that is, agents should forecast inflation correctly on average. Second, forecasts should be efficient-that is, agents should employ all relevant information for which the marginal benefit of gathering and utilizing the information exceeds the marginal cost" (Lloyd, 1999, p. 135). The mean absolute error (MAE) and the root mean square error (RMSE) are the measures of accuracy of forecasts while the mean error (ME) is a measure of unbiasedness of expectations. Lloyd (1999) noted that, it is possible that the results of survey provide a zero mean error, meaning provide unbiasedness of forecasting. But, we cannot say that these results also provide accuracy of inflation expectations. Forsells and Kenny (2002), Mehra (2002) analyzed the rationality of consumers' inflation expectations using these three measures, too. We also begin with these statistics to investigate the forecasting performance. The results of calculations have been given in Table 3 .

So, on the base of the results of Table 3 we found that, the inflation expectation which has been calculated under normality assumption has better performance than other one. On the other hand, we know that for best performance calculated ME must be equal to 0. However it is different from zero for our sample. What about the population? Is the value of this statistics equal to zero in population or not? To answer this question we can use $t$ statistics $^{2}$. We found that, the value of $t$ statistics is significant at 0.01 levels for both assumptions in total case. For the groups, also the same results appeared. Therefore, we can reject null hypothesis. It means that, ME is sufficiently different from zero in population at $99 \%$ level. Thus we defined that expected inflation is biased for both - our sample and population. From Table 2, we can see that individuals had underestimated inflation for all period. Therefore, calculated forecasting errors are negative in both assumptions. On the base of this statement we used only ME and RMSE

\footnotetext{
${ }^{2} t_{M E}=\frac{M E-0}{\sigma_{M E}}$

Where, $\sigma_{M E}=\frac{S}{\sqrt{n}}$, S is a standard deviation of $\Delta_{t}$.
} 
in Table 3. Because, ME and MAE are equal each other in absolute value. It means that, these two values (ME and MAE) have the same distance from zero.

Table 3. Measures of Inflation Forecasting Performance

\begin{tabular}{|c|c|c|c|c|c|c|c|c|c|c|c|c|c|}
\hline \multirow{3}{*}{ Groups } & \multirow{3}{*}{ Subgroups } & \multicolumn{4}{|c|}{$\begin{array}{l}\text { Till first devaluation } \\
\text { (2013Q3-2015Q4) }\end{array}$} & \multicolumn{4}{|c|}{$\begin{array}{l}\text { After first devaluation } \\
\text { (2016O1-2020O1) }\end{array}$} & \multicolumn{4}{|c|}{$\begin{array}{l}\text { For all period (2013Q3- } \\
\text { 2020Q1) }\end{array}$} \\
\hline & & \multicolumn{2}{|c|}{$\mathrm{ME}$} & \multicolumn{2}{|c|}{ RMSE } & \multicolumn{2}{|c|}{ ME } & \multicolumn{2}{|c|}{ RMSE } & \multicolumn{2}{|c|}{$\mathrm{ME}$} & \multicolumn{2}{|c|}{ RMSE } \\
\hline & & n.a & u.a & n.a & u.a & n.a & u.a & n.a & u.a & n.a & u.a & n.a & u.a \\
\hline \multirow{4}{*}{ Income } & $\mathrm{I}<300$ & -0.92 & -0.99 & 0.97 & 1.03 & -1.79 & -2.04 & 2.23 & 2.51 & -1.47 & -1.65 & 1.87 & 2.09 \\
\hline & $300 \leq \mathrm{I}<700$ & -1.00 & -1.06 & 1.05 & 1.12 & -2.51 & -2.68 & 3.02 & 3.26 & -1.95 & -2.08 & 2.48 & 2.67 \\
\hline & $700 \leq \mathrm{I}<1200$ & -0.96 & -1.01 & 1.00 & 1.06 & -2.69 & -2.78 & 3.25 & 3.40 & -2.05 & -2.12 & 2.65 & 2.78 \\
\hline & $1200 \leq \mathrm{I}$ & -1.05 & -1.07 & 1.11 & 1.13 & -3.25 & -3.15 & 4.15 & 4.03 & -2.44 & -2.38 & 3.36 & 3.27 \\
\hline \multirow{7}{*}{ Activity } & Entrepreneurs & -0.89 & -0.97 & 0.94 & 1.02 & -2.48 & -2.60 & 3.01 & 3.18 & -1.89 & -2.00 & 2.45 & 2.60 \\
\hline & Farmers & -1.10 & -1.12 & 1.18 & 1.19 & -2.45 & -2.81 & 3.09 & 3.49 & -1.95 & -2.19 & 2.55 & 2.86 \\
\hline & Official worker & -1.02 & -1.06 & 1.10 & 1.12 & -2.56 & -2.76 & 3.10 & 3.37 & -1.99 & -2.13 & 2.55 & 2.76 \\
\hline & Handicrafts & -1.05 & -1.09 & 1.12 & 1.14 & -2.62 & -2.77 & 3.17 & 3.36 & -2.04 & -2.15 & 2.60 & 2.75 \\
\hline & Worker & -0.95 & -1.03 & 0.99 & 1.09 & -2.09 & -2.30 & 2.58 & 2.85 & -1.67 & -1.83 & 2.14 & 2.36 \\
\hline & Other & -0.98 & -1.05 & 1.02 & 1.10 & -2.25 & -2.50 & 2.73 & 3.04 & -1.78 & -1.96 & 2.25 & 2.51 \\
\hline & Unemp & -1.03 & -1.09 & 1.09 & 1.14 & -2.05 & -2.28 & 2.52 & 2.80 & -1.67 & -1.84 & 2.10 & 2.33 \\
\hline \multirow{2}{*}{$\begin{array}{l}\text { Work } \\
\text { regime }\end{array}$} & Full time & -1.03 & -1.10 & 1.08 & 1.16 & -2.54 & -2.71 & 3.09 & 3.33 & -1.98 & -2.12 & 2.54 & 2.74 \\
\hline & Part time & -0.90 & -0.94 & 0.95 & 0.99 & -2.13 & -2.32 & 2.54 & 2.79 & -1.67 & -1.81 & 2.10 & 2.29 \\
\hline \multirow{3}{*}{ Education } & Primary & -0.95 & -1.04 & 1.00 & 1.09 & -2.44 & -2.71 & 2.93 & 3.25 & -1.89 & -2.10 & 2.40 & 2.67 \\
\hline & Secondary & -0.98 & -1.04 & 1.04 & 1.10 & -2.33 & -2.51 & 2.80 & 3.04 & -1.83 & -1.97 & 2.31 & 2.51 \\
\hline & High & -0.92 & -1.07 & 1.01 & 1.13 & -2.24 & -2.44 & 2.63 & 2.91 & -1.75 & -1.94 & 2.18 & 2.41 \\
\hline \multirow{4}{*}{ Age } & $16-29$ & -0.96 & -1.02 & 1.00 & 1.06 & -2.47 & -2.62 & 3.00 & 3.23 & -1.91 & -2.03 & 2.46 & 2.65 \\
\hline & $30-49$ & -0.97 & -1.04 & 1.02 & 1.10 & -2.37 & -2.57 & 2.86 & 3.12 & -1.85 & -2.00 & 2.35 & 2.56 \\
\hline & $50-64$ & -0.87 & -1.11 & 0.97 & 1.21 & -2.34 & -2.53 & 2.84 & 3.09 & -1.80 & -2.00 & 2.33 & 2.56 \\
\hline & $65+$ & -0.97 & -1.05 & 1.03 & 1.10 & -2.21 & -2.45 & 2.65 & 2.97 & -1.75 & -1.93 & 2.19 & 2.45 \\
\hline \multirow{2}{*}{ Gender } & Male & -1.00 & -1.06 & 1.06 & 1.11 & -2.38 & -2.56 & 2.88 & 3.12 & -1.87 & -2.00 & 2.37 & 2.57 \\
\hline & Female & -0.90 & -0.98 & 0.95 & 1.03 & -2.20 & -2.43 & 2.64 & 2.95 & -1.72 & -1.89 & 2.18 & 2.42 \\
\hline Total & Total & -0.98 & -1.04 & 1.04 & 1.10 & -2.34 & -2.53 & 2.83 & 3.09 & -1.84 & -1.98 & 2.33 & 2.54 \\
\hline
\end{tabular}

Note: $\mathrm{ME}=\frac{\sum_{t=1}^{n} \Delta_{t}}{n}, M A E=\frac{\sum_{t=1}^{n}\left|\Delta_{t}\right|}{n}, R M S E=\left[\frac{\sum_{t=1}^{n} \Delta_{t}^{2}}{n}\right]^{1 / 2}$, n.a - normality assumption, u.a uniform assumption

Where, $n$ is the number of time periods. $\Delta_{t}$ is the forcasting error in time $t$ and is assigned as the forecast inflation rate $\left(\pi_{t}^{e}\right)$ minus the actual inflation rate $\left(\pi_{t}\right), \Delta_{t}=\pi_{t}^{e}-\pi_{t}$.

Continuing the analysis over the groups we will calculate average of ME and RMSE for each group. So, we summarized the results of mentioned calculations in Table 4.

Table 4. Mean value of ME and RMSE

\begin{tabular}{lcccc}
\hline \multirow{2}{*}{ Groups (i) } & \multicolumn{3}{c}{ Mean values } \\
\cline { 2 - 5 } & \multicolumn{2}{c}{ Under normality assumption } & \multicolumn{2}{c}{ Under uniform assumption } \\
\cline { 2 - 5 } & $\overline{M E}_{i}$ & $\overline{R M S E}_{i}$ & $\overline{M E}_{i}$ & $\overline{R M S E}_{i}$ \\
\hline Income & -1.98 & 2.59 & -2.06 & 2.70 \\
\hline Activity & -1.86 & 2.38 & -2.01 & 2.59 \\
\hline Work rejime & -1.83 & 2.32 & -1.96 & 2.52 \\
\hline Education & -1.82 & 2.30 & -2.00 & 2.53 \\
\hline Age & -1.83 & 2.33 & -1.99 & 2.56 \\
\hline Gender & -1.80 & 2.27 & -1.95 & 2.54 \\
\hline Total & -1.84 & 2.33 & -1.98 & \\
\hline
\end{tabular}

Note: $\overline{M E}_{i}=\frac{\sum_{i} M E_{i}}{N_{i}}, \overline{R M S E}_{i}=\frac{\sum_{i} R M S E_{i}}{N_{i}}$

Where, $\mathrm{N}_{\mathrm{i}}$ is a number of subgroups in each group, $i$ indicates the groups.

Table 4 shows that, all groups and total have better performance based on both $\overline{M E}_{i}$ and $\overline{R M S E}_{i}$ under normality assumtion than uniform assumption. On the other hand, for both - 
normality assumption and uniform assumption Education group has the best performance based on both statistic values.

\section{Regression analysis for unbiasedness}

The predicted inflation is below or above the current inflation because biased expectations, on average. There is a widespread approach to test the bias. This approach is based on the regresses the actual inflation rate $\left(\pi_{t}\right)$ on the (previously made) forecast of inflation $\left(\pi_{t}^{e}\right)$. Mankiw etc. (2003), Lloyd (1999), Lyziak (2003), Dias et al. (2010) etc. have used this approach in their research. On the base of these papers, we can write the mentioned equation as the following:

$$
\pi_{t}=\beta_{0}+\beta_{1} \pi_{t}^{e}+\varepsilon_{t}
$$

Where, $\pi_{t}$ is the actual (current) inflation rate, $\pi_{t}^{e}$ is the forecast of inflation (expected inflation), $\beta_{0}$ and $\beta_{1}$ are corresponding coefficients, $\varepsilon_{t}$ is the error term of the regression.

Unbiased expectations consider that rational individuals do not execute systematic and continual errors on the forecasting inflation. So, when individuals don't execute these errors, then we can accept the joint null hypothesis that $\beta_{0}=0$ and $\beta_{1}=1$. But, acceptance of this hypothesis can't indicate those individuals' forecasts is accurate or not. This phenomenon relates the existence of serial correlation in the error term in equation (4.1). The results of the estimation of (4.1) are in Table 5. We can see from Table 5, $\beta_{1}$ is significant at 0.01 confidence level in all equations while $\beta_{0}$ is insignificant in some equations. The coefficient of determination $\left(R^{2}\right)$ is very high for all equations. It looks like spurious result and may be related with the non-stationary time series. The result of Chi-squared statistics indicates that the null hypothesis $\left(\mathrm{H}_{0}:\left(\beta_{0}, \beta_{1}\right)=(0,1)\right)$ of unbiasedness is rejected at conventional significance levels. It means that, forecast of inflation expectation had been biased for period of 2013Q3-2020Q1.

Table 5. The results of regression analysis for unbiasedness

\begin{tabular}{|c|c|c|c|c|c|}
\hline \multicolumn{6}{|c|}{$\pi_{t}=\beta_{0}+\beta_{1} \pi_{t}^{e}+\varepsilon_{t}$} \\
\hline Groups & $\frac{\pi_{t}^{e}}{\text { Subgroups }}$ & $\beta_{0}$ & $\beta_{1}$ & $R^{2}$ & $\chi^{2}$ \\
\hline \multirow{4}{*}{ Income } & $\mathrm{I}<300$ & $0.65(0.14)$ & $1.20(0.00)$ & 0.96 & $13.7(0.00)$ \\
\hline & $300 \leq \mathrm{I}<700$ & $0.40(0.48)$ & $1.43(0.00)$ & 0.98 & $121.0(0.00)$ \\
\hline & $700 \leq \mathrm{I}<1200$ & $0.25(0.58)$ & $1.52(0.00)$ & 0.98 & $554.6(0.00)$ \\
\hline & $1200 \leq \mathrm{I}$ & $-0.36(0.12)$ & $1.91(0.00)$ & 0.96 & $109.1(0.00)$ \\
\hline \multirow{7}{*}{ Activity } & Entrepreneurs & $0.34(0.41)$ & $1.43(0.00)$ & 0.97 & $60.6(0.00)$ \\
\hline & Farmers & $0.86(0.07)$ & $1.31(0.00)$ & 0.91 & $11.3(0.003)$ \\
\hline & Official worker & $0.33(0.34)$ & $1.47(0.00)$ & 0.98 & $114.5(0.00)$ \\
\hline & Handicrafts & $0.69(0.04)$ & $1.39(0.00)$ & 0.94 & $42.6(0.00)$ \\
\hline & Worker & $0.47(0.11)$ & $1.31(0.00)$ & 0.96 & $23.0(0.00)$ \\
\hline & Other & $0.55(0.09)$ & $1.33(0.00)$ & 0.96 & $29.4(0.00)$ \\
\hline & Unemployment & $0.80(0.10)$ & $1.23(0.00)$ & 0.96 & $80.5(0.00)$ \\
\hline \multirow{2}{*}{ Work regime } & Full time & $0.37(0.57)$ & $1.45(0.00)$ & 0.98 & $68.7(0.00)$ \\
\hline & Part time & $0.52(0.14)$ & $1.30(0.00)$ & 0.97 & $44.3(0.00)$ \\
\hline \multirow{3}{*}{ Education } & Primary & $0.50(0.20)$ & $1.38(0.00)$ & 0.97 & $109.7(0.00)$ \\
\hline & Secondary & $0.50(0.20)$ & $1.36(0.00)$ & 0.97 & $40.6(0.00)$ \\
\hline & High & $0.56(0.00)$ & $1.32(0.00)$ & 0.98 & $50.9(0.00)$ \\
\hline \multirow{4}{*}{ Age } & $16-29$ & $0.44(0.52)$ & $1.41(0.00)$ & 0.96 & $407.7(0.00)$ \\
\hline & $30-49$ & $0.45(0.13)$ & $1.38(0.00)$ & 0.97 & $59.1(0.00)$ \\
\hline & $50-64$ & $0.39(0.03)$ & $1.38(0.00)$ & 0.96 & $94.3(0.00)$ \\
\hline & $65+$ & $0.51(0.08)$ & $1.33(0.00)$ & 0.97 & $42.4(0.00)$ \\
\hline \multirow{2}{*}{ Gender } & Male & $0.47(0.28)$ & $1.38(0.00)$ & 0.97 & $39.6(0.00)$ \\
\hline & Female & $0.39(0.16)$ & $1.35(0.00)$ & 0.98 & $77.4(0.00)$ \\
\hline Total & Total & $0.46(0.28)$ & $1.37(0.00)$ & 0.97 & $42.5(0.00)$ \\
\hline
\end{tabular}


Notes: Figures in parentheses are $p$ values. $n$ is number of observations. Chi-squared statistics pertain to null hypothesis $\mathrm{H}_{0}:\left(\beta_{0}, \beta_{1}\right)=(0,1)$. Equations are estimated by OLS using covariance matrix corrections suggested by Newey and West (1987).

\section{Conclusion}

The household survey data was used for the estimation of inflation expectations in Azerbaijan. Normal and uniform distributions had been chosen for the calculation of inflation expectations from 2013Q3 through 2020Q1. According to the results, the forecasting error under the normality assumption was less than the forecasting error under the uniform assumption. Also, the regression analysis for unbiasedness illustrated a statistically significant relationship between the current actual inflation rates. However, the chi-square statistics indicated that the null hypothesis of unbiasedness was rejected at conventional significance levels.

Assumed the expectations might be rational, additional studies for the efficiency of the expectations were required. The efficiency was not investigated in this paper due to the lack of the required time series.

Overall, the estimation of aggregate household inflation expectations showed that inflation would increase for all quarters of 2020, and the tendency would continue even in 2021 .

\section{References}

Arioli, R., Bates, C., Dieden, H., Duca, I., Friz, R., Gayer, C., Kenny, G., Meyler, A., \& Pavlova, I. (2017). EU consumers' quantitative inflation perceptions and expectations: an evaluation. Occasional Paper Series of the European Central Bank, No 186.

Armona, L., Fuster, A., ? Zafar, B. (2019). Home Price Expectations and Behaviour: Evidence from a Randomized Information Experiment. The Review of Economic Studies, 86(4), 1371-1410.

Arnold, I. J. M., \& Lemmen, J. J.G. (2008). Inflation Expectations and Inflation Uncertainty in the Eurozone: Evidence from Survey Data. Review of World Economics / Weltwirtschaftliches Archiv, 144(2), 325-346.

Batchelor, R. A., \& Orr, A. B. (1988). Inflation Expectations Revisited. Economica, New Series, 55(219), 317-331.

Carlson, J. A., \& Parkin, M. (1975). Inflation Expectations. Economica, New Series, 42(166), 123-138.

Dias, F., Duarte, C., \& Rua, A. (2010). Inflation expectations in the euro area: are consumers rational? Review of World Economics / Weltwirtschaftliches Archiv, 146(3), 591-607.

Diamond , J., Watanabe, K., \& Watanabe, T. (2020). The formation of consumer inflation expectations: new evidence from japan's deflation experience. International Economic Review, 61(1), DOI: 10.1111/iere.12423

Drager, L. (2015). Inflation perceptions and expectations in Sweden-Are media reports the missing link? Oxford Bulletin of Economics and Statistics, 77(5), 681-700.

Ehrmann, M., Damjan P., \& Emiliano, S. (2015). Consumers' Attitudes and Their Inflation Expectations. Finance and Economics, Discussion Series, 2015-015. Washington: Board of Governors of the Federal Reserve System. 
Forsells, M., \& Kenny, G. (2002). The rationality of consumers' inflation expectations: Surveybased evidence for the euro area. European Central Bank, Working Paper series No. 163, Frankfurt.

Friedman, M. (1968). The Role of Monetary Policy. The American Economic Review, 58(1). (Mar., 1968), 1-17.

Hasanli, Y., Abbasov, J., \& Yusifov, M. (2015). Implementation of Equilibrium-Price Model to the Estimation of Import Inflation. International Journal of Business and Social Research, 05(04), 1-8.

Hasanov, F. (2011). Relationship between Inflation and Economic Growth in Azerbaijani Economy: Is There Any Threshold Effect? Asian Journal of Business and Management Sciences, 1(1), 1-11

Johannsen, B. K. (2014). Inflation Experience and Inflation Expectations: Dispersion and Disagreement within Demographic Groups. Finance and Economics Discussion Series 2014-89, U.S. Board of Governors of the Federal Reserve System.

Kaplan, G., \& Schulhofer-Wohl, S. (2017). Inflation at the Household Level. Journal of Monetary Economics, 91, 19-38.

Knöbl, A. (1974). Price Expectations and Actual Price Behavior in Germany. Staff Papers (International Monetary Fund), 21(1), 83-100.

Kokoszczynski, R., Łyziak, T., \& Stanisławska, E. (2010). Consumer inflation expectations: Usefulness of survey-based measures-A cross-country survey. In P. Sinclair (ed.), Inflation expectations (pp. 76-100). Oxford: Routledge.

Lloyd, B. T. (1999). Survey Measures of Expected U.S. Inflation. The Journal of Economic Perspectives, 13(4), 125-144.

Łyziak, T. (2003). Consumer inflation expectations in Poland. European Central Bank, working paper No. 287, November 2003.

Łyziak, T. (2009). Measuring consumer inflation expectations in Europe and examining their forward-lookingness (MPRA Paper, 18890). Munich: Personal RePEc Archive.

Łyziak, T. (2010). Measurement of perceived and expected inflation on the basis of consumers survey data (Irving Fisher Committee on Central Bank Statistic Working Papers, 5). Basel: Bank for International Settlements.

Łyziak, T. (2013). Formation of inflation expectations by different economic agents. The case of Poland. Eastern European Economics, 51(6), 5-33.

Łyziak, T., \& Mackiewicz-Łyziak, J. (2014). Do consumers in Europe anticipate future inflation? Has it changed since the beginning of the financial crisis? Eastern European Economics, 52(3), 5-32.

Mankiw, N. G., Ricardo, R., \& Wolfers, J. (2003). Disagreement about Inflation Expectations. NBER Macroeconomics Annual, 18 (2003), 209-248.

Mehra, Y. P. (2002). Survey measures of expected inflation: revisiting the issues of predictive content and rationality, in: "Economic Quarterly", 88/3, Federal Reserve Bank of Richmond, pp. 17-36.

Miah, F., Rahman, S., \& Albinali, K. (2016). Rationality of survey based inflation expectations: A study of 18 emerging economies' inflation forecasts. Research in International Business and Finance, 36, 158-166.

Muth, J. F. (1961). Rational Expectations and the Theory of Price Movements. Econometrica, 29(3) (Jul., 1961), 315-335. 
Rahimov, V., Adigozalov, S., \& Mammadov, F. (2016). Determinants of Inflation in Azerbaijan. Working Papers 1607, Central Bank of Azerbaijan Republic.

Szyszko, M., Rutkowska, A., \& Kliber, A. (2020). Inflation expectations after financial crisis: are consumers more forward-looking? Economic Research - Ekonomska Istraživanja, 33(1), 1052-1072.

Theil, H. (1952). On the Time Shape of Economic Micro variables and the Munich Business Test. Review of the International Statistical Institute, 20(2) (1952), 105-120.

Ueno, Y., \& Namba, R. (2013). Disagreement and Biases in Inflation Expectations of Japanese Households (in Japanese). ESRI Discussion Papers No.300, Economic Research Institute, Cabinet Office, Government of Japan. 